\title{
Prevalence of intestinal parasites and risk factors for specific and multiple helminth infections in a remote city of the Brazilian Amazon
}

\author{
Alessandra Queiroga Gonçalves ${ }^{[1],[2]}$, Angela Cristina Verissimo Junqueira ${ }^{[1]}$, \\ Rosa Abellana ${ }^{[2]}$, Patricia Comella del Barrio ${ }^{[2]}$, Wagner Cosme Morhy Terrazas ${ }^{[3]}$, \\ Fernando Campos Sodréé[ ${ }^{[4]}$, Márcio Neves Bóia ${ }^{[1],[5],[6]}$ and Carlos Ascaso ${ }^{[2],[7]}$
}

\begin{abstract}
[1]. Laboratório de Doenças Parasitárias, Instituto Oswaldo Cruz, Fundação Oswaldo Cruz, Rio de Janeiro, Rio de Janeiro, Brasil. [2]. Departament de Salut Pública, Facultat de Medicina, Universitat de Barcelona, Barcelona, Spain. [3]. Fundação de Vigilância em Saúde do Amazonas, Manaus, Amazonas, Brasil. [4]. Departamento de Patologia, Universidade Federal Fluminense, Niterói, Rio de Janeiro, Brasil. [5]. Programa de Pós-Graduação em Medicina Tropical, Instituto Oswaldo Cruz, Fundação Oswaldo Cruz, Rio de Janeiro, Rio de Janeiro, Brasil. [6]. Laboratório de Biologia e Parasitologia de Mamíferos Silvestres Reservatórios, Fundação Oswaldo Cruz, Rio de Janeiro, Rio de Janeiro, Brasil. [7]. Institut d'Investigacions Biomèdiques August Pi i Sunyer, Barcelona, Spain.
\end{abstract}

\begin{abstract}
Introduction: Few studies have described the risk factors of intestinal parasitic infections in the Amazon. Methods: A crosssectional survey was performed in a City of the State of Amazonas (Brazil) to estimate the prevalence of intestinal parasites and determine the risk factors for helminth infections. Results: Ascaris lumbricoides was the most prevalent parasite. The main risk factors determined were: not having a latrine for A. lumbricoides infection; being male and having earth or wood floors for hookworm infection; and being male for multiple helminth infections. Conclusions: We reported a high prevalence of intestinal parasites and determined some poverty-related risk factors.
\end{abstract}

Keywords: Protozoan infections. Helminthiasis. Risk factors.

Soil-transmitted helminth infections are considered among the most common infections in humans and account for a substantial disease burden in the poor populations living in remote or rural areas, urban slums, or in conflict zones ${ }^{(1)}$. In addition, some protozoan infections, such as giardiasis and amoebiasis, are also associated with considerable morbidity.

The Northern region of Brazil presents remote areas in which inappropriate living conditions are an important public health issue. The Amazon is situated in this region and presents environmental characteristics that are favorable for the development of stages of soil-transmitted helminths $(\mathrm{STH})^{(2)}$. A high prevalence of intestinal parasites has been reported in rural communities and in small urbanized cities of the Brazilian Amazon presenting limited sanitation and hygiene practices ${ }^{(3)(4)}$. Nevertheless, few studies concerning the risk factors related to infections by intestinal parasites in amazonian populations have been published to date ${ }^{(5)(6)}$, with none of these studies being performed in remote areas.

At present little is known about the determinants of patterns of infection by multiple helminth species within communities ${ }^{(7)}$

Corresponding author: Dra. Alessandra Queiroga Gonçalves. e-mail: alequeiroga@gmail.com

Received 17 April 2015

Accepted 8 July 2015 and to date no study has addressed the risk factors for multiparasitism in Amazonian populations. The aim of this study was to determine the prevalence of helminth and intestinal protozoa and the risk factors for specific and multiple helminth infections in a remote city of the Amazon region of Brazil.

This study was performed in Barcelos City $\left(0^{\circ} 58^{\prime} \mathrm{S}\right.$; $62^{\circ} 56^{\prime} \mathrm{W}$ ), located in the municipality of Barcelos, in the state of Amazonas, Northern Brazil. This remote city is situated in the middle of an extensive area of preserved tropical rainforest, on the right bank of the Negro River, and had a total of 4.022 inhabitants distributed in 727 households $^{(8)}$.

A cross-sectional coproparasitologic study was performed in the city in July 1997. The sample size of the prevalence study, calculated from an estimation of $50 \%$ for intestinal parasites with a confidence level of $95 \%$ and precision of $5 \%$, was determined to be 351 subjects. Through systematic sampling by familiar conglomerates, one in four inhabited households was selected for the study, which consisted in a total of 194 households with 996 inhabitants.

Demographic data and the characteristics of the households were collected using a questionnaire. All the inhabitants of the selected households were invited to participate in the study and to provide one fresh stool sample. Stool samples were evaluated using the spontaneous sedimentation technique ${ }^{(9)}$ and the Rugai, Mattos, and Brisola technique ${ }^{(10)}$ in a local laboratory.

In the statistical analyses, the confidence intervals were computed using normal or Poisson distribution. The relationship 
between infection by intestinal parasites and the variables sex, age group, and neighborhood was assessed using the Chi-squared or the Fisher exact tests. In order to evaluate the association between the presence of helminth infection (A. lumbricoides, hookworm, and Trichuris trichiura) and the studied factors, univariable and a multivariable logistic regression analyses with random effects were used, taking into account that the members of the same household are not independent. To evaluate the relationship between the multi-categorical variable multiple helminth infections and the independent variables, univariable and multivariable multinomial regression analyses with household clustering as random effects were considered. Statistical significance was assumed at a p-value $<0.05$. The statistical analyses were performed using IBM SPSS statistics 20 software and SAS software (version 9.3).

Subjects infected with pathogenic intestinal parasites received appropriate treatment during the fieldwork. This study was approved by the Ethics Committee in Investigation of the Instituto de Pesquisa Clínica Evandro Chagas, Fundação Oswaldo Cruz (Protocol CAAE 0030.0.009.000-08).

Of the 194 households selected, 137 participated in the study. In these households, 594 (74.1\%) out of a total of 801 inhabitants submitted a stool sample for the diagnosis of helminth and intestinal protozoa. On comparing the neighborhoods, the no-returning of samples by the households was similar among all the neighborhoods, constituting a random loss (Kruskal Wallis $=2.790, p=0.732$ ). All the samples were submitted to the spontaneous sedimentation technique, but only $27.3 \%$ were processed by the Rugai, Mattos, and Brisola technique owing to the lack of sufficient fecal sample.

Overall, 77.9\% (463/594) of the population was infected with at least one species of helminth or intestinal protozoan. Infections by helminths predominated $(65.3 \%)$. Ascaris lumbricoides, hookworm, and T. trichiura were the most common helminths. Amoebas from the Entamoeba histolytica complex and Giardia lamblia were the most prevalent potential pathogenic protozoa. The commensals Entamoeba coli (11.3\%), Endolimax nana (11.3\%), and Iodamoeba butschlii (6.4\%) were also found.

The overall prevalence of infection was equal between the sexes $(\mathrm{p}=0.789)$. However, infections by Strongyloides stercoralis and hookworms were higher in men. Significant associations were reported with the age group in Ascaris lumbricoides, hookworm, T. trichiura, and G. lamblia infections. There was significant variation between the neighborhoods in relation to infection by $A$. lumbricoides, hookworm, and T. trichiura. Almost half of the population presented multiple infections by helminth and/or intestinal protozoa and $24.6 \%$ presented multiple helminth infections. Infection by single or multiple helminth species differed between the sexes. Both types of multiple infections considered were associated with age groups and neighborhoods (Table 1).

The risk factors associated with Ascaris lumbricoides infections were age groups, not having a latrine and not having a means of transport. All the age groups had a greater risk of infection than the children less than 5 years old.

Regarding hookworm infections, all the age groups presented a higher risk of infection than the 0-5 year age group.
Moreover, being male and having earth or wood floors in the household showed a greater risk of hookworm infection. With respect to the neighborhood of Centro, the neighborhoods of Nazaré, São Lázaro, and São Sebastião presented a higher risk of hookworm infections.

The risk factors found for Trichuris trichiura infections were being 6-14 years of age and living in Aparecida (Table 2).

Males were more likely to be multi-infected than females. All age groups had a greater risk of having single and multiple infection by helminths than the 0-5 years age group. People living in the neighborhoods of Aparecida, Nazaré and São Lázaro had a high risk of having multiple infections by helminths and those who did not have any means of transport were more likely to be multiparasitized (Table 3).

The high overall prevalence of infections with helminth and intestinal protozoa observed in our study corroborates previous studies from the micro-region of the Negro River in the State of Amazonas, which reported prevalence between $69.3 \%$ and

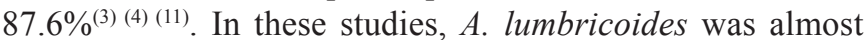
always the most prevalent in comparison with other intestinal pathogenic parasites, with the prevalence ranging from $19.3 \%$ in the municipality of São Gabriel da Cachoeira (Iauaretê) to $51 \%$ in the City of Barcelos ${ }^{(3)(12)}$. The E. histolytica complex was the next in most frequent, with prevalence of $7.3 \%$ to $34 \%{ }^{(11)(13)}$. The prevalence of other helminths, such as $S$. stercoralis, hookworm, and $T$. trichiura also varied in several studies. In the Amazon, regional differences in prevalence could be due to variations in human exposure in different epidemiological scenarios that could be dependent on local environmental conditions (such as soil type - sandy or clayed soil, shading of soil, and humidity), climatic conditions (e.g. temperature and rainfall), work-related activities (such as agricultural work associated with the practice of open defecation) and sanitation ${ }^{(2)}$.

The lack of a latrine was a risk factor for Ascaris lumbricoides infection. One possible explanation for the fact that only infection by $A$. lumbricoides was associated with the lack of a latrine may be owing to its high prevalence in our study, and thus, the data related to this helminth has greater statistical power to detect associations.

After the development of the present study, our research group performed a bacteriological analysis of water from the 8 public artesian wells that supply almost the entire city. All the wells had water suitable for human consumption (data not published). Since $90.8 \%$ of the studied households consumed water from public wells, we can therefore suppose that they consumed water of good quality. In our study, the use of water from a private well or stream by a few households did not appear as a risk factor. This result added to the lack of latrines in $49.6 \%$ of the households evaluated and the presence of open sewage ditches throughout the city suggests that the transmission of intestinal parasites in the city could mainly be caused by soil contamination by human feces.

Concerning the risk factors found to be related to hookworm infection, we observed that the frequency of infection was higher in men than in women, corroborating previous studies ${ }^{(14)}$. We also observed that people living in households with earth 


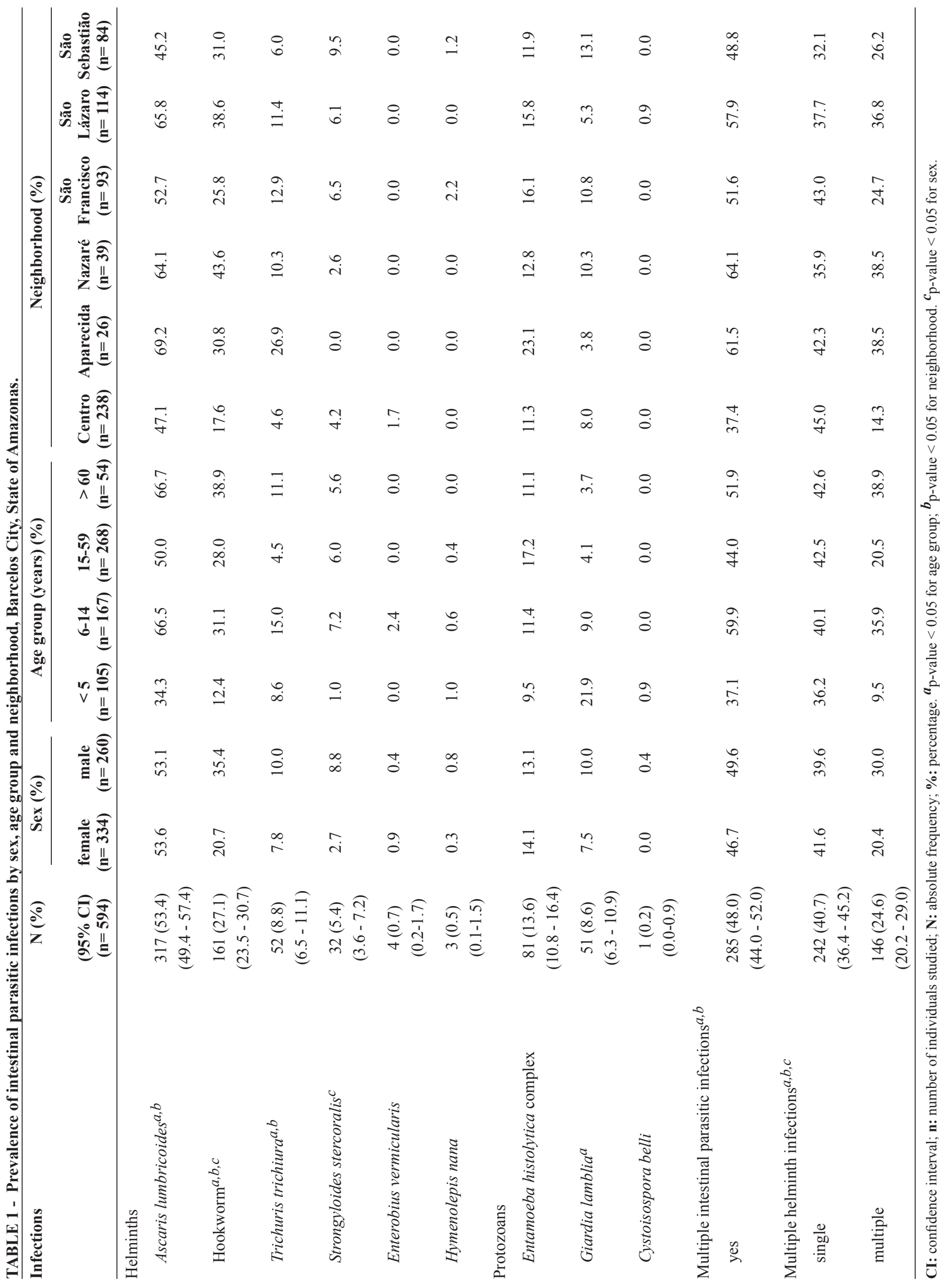


TABLE 2 - Results of multivariable logistic regression models for risk factors of specific helminth infections in Barcelos City, State of Amazonas.

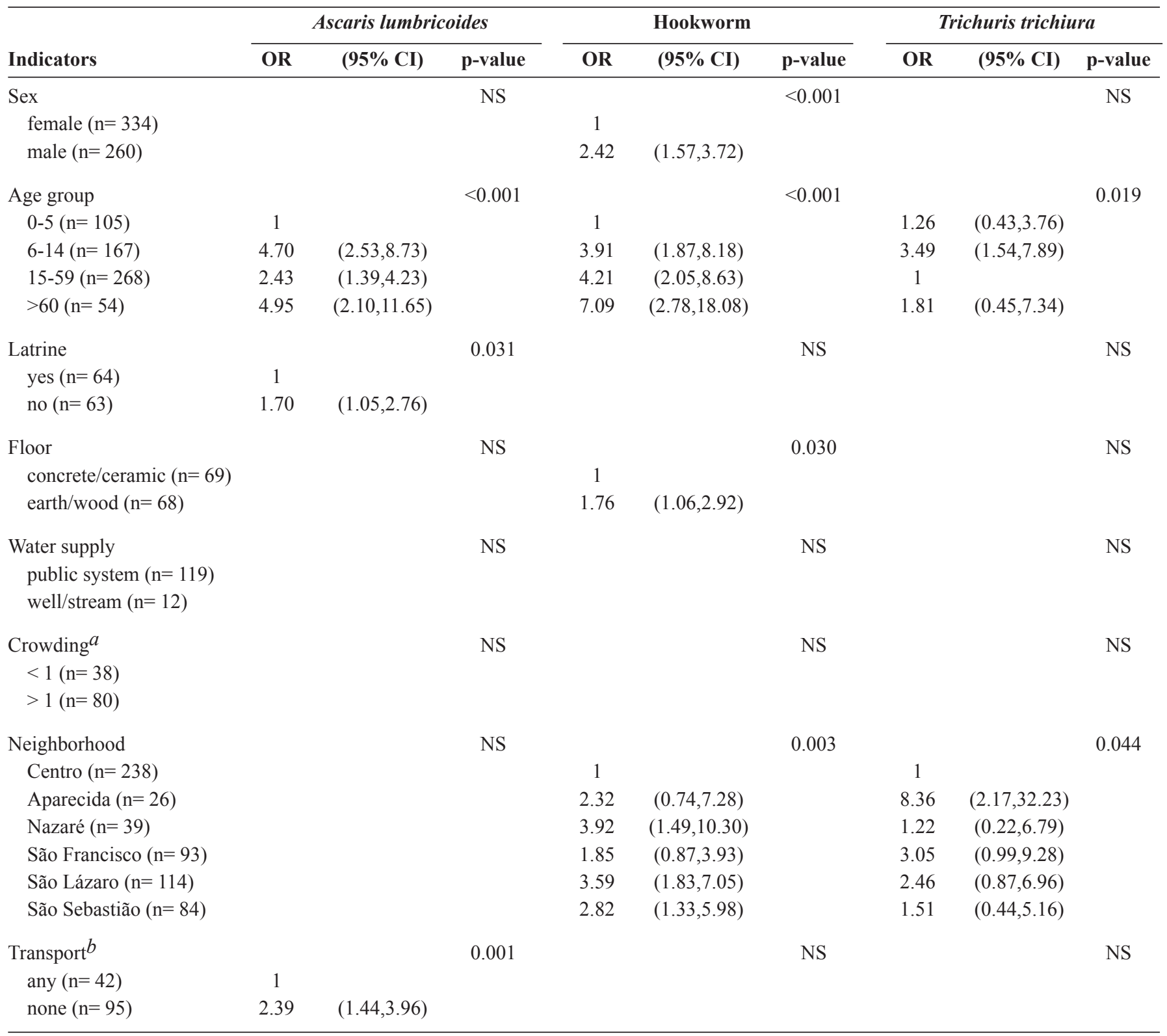

n: number of subjects or houses; CI: confidence interval; NS: not significant; OR: odds ratio; $\boldsymbol{a}_{\text {room/person; }} \boldsymbol{b}_{\text {bicycle, motorcycle or car. }}$

or wood floors were more frequently infected by hookworm. Previous studies have reported a significant association between housing characteristics and infections with $\mathrm{STH}^{(15)}$. On the other hand, Pullan et al. ${ }^{(7)}$ found that flooring material as a variable was no longer associated with co-infection with Necator americanus and Schistosoma mansoni when the socio-economic status was considered in the analysis, thus constituting a problem of colinearity between these variables. We found that the variable of flooring material was not associated with the variable used as a socio-economic indicator (having a means of transport), thereby indicating that flooring as a variable in our study is probably related to the transmission of hookworm.
We considered the possession of a means of transport as a socio-economic indicator because our population was homogenous with respect to having typical household assets such as a television and refrigerator, making it difficult to construct a socio-economic indicator based on this parameter. The variable of having a means of transport was considered to be a valid socio-economic indicator in our study because on descriptive analysis we observed that this variable showed a different distribution among the neighborhoods. The multivariable model demonstrated that people without any kind of transport, precisely the poorest people in the city, presented a higher risk of $A$. lumbricoides and multiple helminth infections. 
TABLE 3 - Results of multivariable multinomial regression model for risk factors of single and multiple helminth infections in Barcelos City, State of Amazonas.

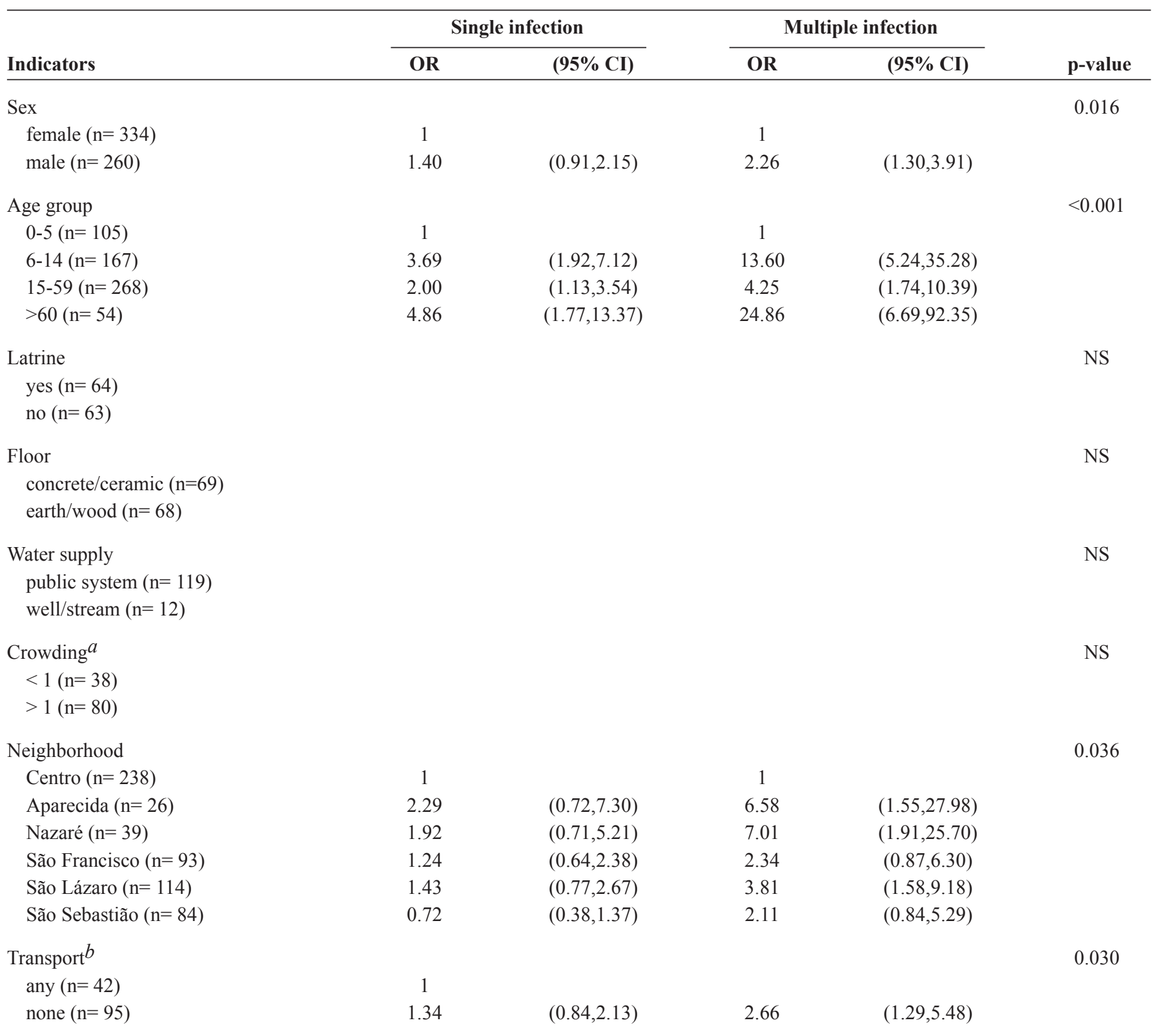

n: number of subjects or houses; CI: confidence interval; NS: not significant; OR: odds ratio; $\boldsymbol{a}_{\text {room/person; }} \boldsymbol{b}_{\text {bicycle, motorcycle or car. }}$

The risk of helminth infection varied among the neighborhoods and we identified four neighborhoods presenting a high risk of infection (by multiple helminth species, hookworm, or T. trichiura). However, the risk of $A$. lumbricoides infection was not associated with neighborhood, thereby suggesting widespread dispersion of this highly prevalent helminth in the city.

In the present study we report a high prevalence of intestinal parasites. To our knowledge, this is the first study to determine the risk factors related to intestinal infection by $A$. lumbricoides, hookworm, T. trichiura, and multiple helminth species in a city of the Brazilian Amazon. It is important to note that to date local sanitation programs and periodic deworming campaigns have not been implemented in the city. In addition to sanitation, improvement of environmental hygiene, periodic chemotherapy, and health education must be implemented.

\section{CONFLICT OF INTEREST}

The authors declare that there is no conflict of interest. 


\section{FINANCIAL SUPPORT}

Federal scholarships from the Conselho Nacional de Desenvolvimento Cientifico e Tecnológico (CNPq) and the Coordenação de Aperfeiçoamento de Pessoal de Nível Superior (CAPES).

\section{ACKNOWLEDGMENTS}

The authors would like to thank the post graduate course of tropical medicine from the Instituto Oswaldo Cruz (Fiocruz, Rio de Janeiro, Brazil) for support of the fieldwork. Lucilaide O. Santos, Rodolfo Devera, Claudina R. de Bonfante and José Eduardo B. Campos for participation in the fieldwork.

\section{REFERENCES}

1. Hotez PJ, Fenwick A, Savioli L, Molyneux DH. Rescuing the bottom billion through control of neglected tropical diseases. Lancet 2009; $373: 1570-1575$

2. Confalonieri UEC, Margonari C, Quintão AF. Environmental change and the dynamics of parasitic diseases in the Amazon. Acta Trop 2014; 129:33-41.

3. Coura JR, Willcox HP, Tavares AM, de Paiva DD, Fernandes O, Rada EL, et al. Epidemiological, social, and sanitary aspects in an area of the Rio Negro, State of Amazonas, with special reference to intestinal parasites and Chagas' disease. Cad Saude Publica 1994; 10 (suppl 2):327-336.

4. Bóia MN, da Motta LP, Salazar MD, Mutis MP, Coutinho RB, Coura JR. Cross-sectional study of intestinal parasites and Chagas' disease in the Municipality of Novo Airão, State of Amazonas, Brazil. Cad Saude Publica 1999; 15:497-504.

5. Benetton MLFN, Gonçalves AV, Meneghini MEF, Silva EF, Carneiro M. Risk factors for infection by the Entamoeba histolytica/E. dispar complex: an epidemiological study conducted in outpatient clinics in the city of Manaus, Amazon Region, Brazil. Trans R Soc Trop Med Hyg 2005; 99:532-540.

6. Maia MMM, Fausto MA, Vieira ELM, Benetton MLFN, Carneiro M. Intestinal parasitic infection and associated risk factors, among children presenting at outpatient clinics in Manaus, Amazonas state, Brazil. Ann Trop Med Parasitol 2009; 103:583-591.

7. Pullan RL, Bethony JM, Geiger SM, Cundill B, Correa-Oliveira R, Quinnell RJ, et al. Human helminth co-infection: analysis of spatial patterns and risk factors in a Brazilian community. PLoS Negl Trop Dis 2008; 2:e352.

8. Instituto Brasileiro de Geografia e Estatística. (IBGE). Censo demográfico 1991. (Accessed 2015 Jun 25). Available at: http:// seriesestatisticas.ibge.gov.br/series.aspx? vcodigo $=\mathrm{CD} 91$.

9. Lutz A. Schistosomum mansoni and Schistosomatosis observed in Brazil. Mem Inst Oswaldo Cruz 1919; 11:121-155.

10. Rugai E, Mattos T, Brisola AP. Nova técnica para isolar larvas de nematóides das fezes - modificaçao do método de Baermann. Rev Inst A Lutz 1954; 14:5-8.

11. Rios L, Cutolo SA, Giatti LL, Castro M, Rocha AA, Toledo RF, et al. Prevalência de parasitos intestinais e aspectos socioambientais em comunidade indígena no distrito de Iauaretê, Município de São Gabriel da Cachoeira (AM), Brasil. Saúde Soc São Paulo 2007; 16:76-86.

12. Bóia MN, Carvalho-Costa FA, Sodré FC, Porras-Pedroza BE, Faria EC, Magalhães GAP, et al. Tuberculose e parasitismo intestinal em população indígena na Amazônia brasileira. Rev Saude Publica 2009; 43:176-178

13. Bóia MN, Carvalho-Costa FA, Sodré FC, Eyer-Silva WA, Lamas CC, Lyra MR, et al. Mass treatment for intestinal helminthiasis control in an Amazonian endemic area in Brazil. Rev Inst Med Trop São Paulo 2006; 48:189-195.

14. Raso G, Vounatsou P, Gosoniu L, Tanner M, N'Goran EK, Utzinger J. Risk factors and spatial patterns of hookworm infection among schoolchildren in a rural area of western Côte d'Ivoire. Int J Parasitol 2006; 36:201-210.

15. Raso G, Utzinger J, Silué KD, Ouattara M, Yapi A, Toty A, et al. Disparities in parasitic infections, perceived ill health and access to health care among poorer and less poor schoolchildren of rural Côte d'Ivoire. Trop Med Int Health 2005; 10:42-57. 